\title{
What place does compassion hold in the conduct and production of health services research?
}

\author{
Stephanie Tierney
}

\begin{abstract}
Compassion is a word that conveys a sense of action taking place in response to suffering or distress. Over recent years we have seen considerable international debate surrounding compassion within healthcare practice. However, the topic of compassion has been little discussed in terms of the production of health services research. This paper seeks to address this gap by raising compassion within health services research as an area warranting consideration by those planning, managing and conducting such work. It considers compassion towards study participants when recruiting, collecting and analysing data, and also in relation to researchers involved in day to day activities associated with executing a project. Research leaders play a role in ensuring that compassion is not overlooked for those who provide or collect and interpret data. Furthermore, self-compassion could be fostered among researchers to buffer against the everyday activities of their job that have the potential to cause anxiety and distress.
\end{abstract}

Keywords: Compassion, Health services research, Participant distress, Self-compassion

\section{Background}

As a concept, compassion involves noticing and tolerating of distress or suffering and then acting to alleviate or prevent this [1]. From an evolutionary perspective, compassion has been related to human advancement in terms of being able to image, anticipate and cogitate [1]. This is said to have facilitated nurturing and caregiving; as humans became able to appreciate how others might be feeling and why, it motivated them to notice and try to alleviate or prevent distress or discomfort [1]. This evolved ability to connect with others has been associated with reproduction and survival of offspring [2]. In that sense, compassion emphasises the interactive nature of being, and the interdependence and vulnerability of humans. Alongside being able to respond to the needs of others, it is argued that humans also evolved the capacity to show compassion to the self [3]. This notion of self-compassion has been segmented into three main components - self-kindness, common humanity, and mindfulness [4]. It entails accepting one's suffering as part of the broader human condition,

Correspondence: stephanie.tierney@warwick.ac.uk

Warwick Medical School, University of Warwick, Gibbet Hill Campus, Coventry CV4, 7AL, UK adopting a non-judgmental stance, and using self-kindness as a means of healing [5].

An arena where humans interact on a regular basis is the workplace. Consequently, researchers have explored compassion within organisations, where it is denoted as a process of observing, appraising, feeling and acting [6], or attending, understanding, empathising and helping [7]. Compassion in the workplace has been defined as transformative [8], having a positive impact on people's commitment to their job [9] and how they view their colleagues, as well as helping individuals to deal with their own setbacks and sorrow $[10,11]$. Compassion can augment connections between colleagues and contribute to more productive employees $[10,12]$. Evidence suggests that working in a compassionate culture can foster innovation and psychological safety [7]. Conversely, if people feel that psychosocial safety is lacking in an organisation they can "become self-obsessed, distracted, angry and punitive" [13].

Research by Dutton et al. [14] suggested that organisations do not become compassionate simply by hiring caring people. Instead, a facilitating social architecture is required, "that allows for the emergence of dynamics that generate and coordinate key resources, such as empathetic concern, 
attention, legitimacy, and trust." This relates to social norms, said to be "among the least visible and most powerful forms of social control over human action" [15]. In regards to social norms, leaders can set the tone that it is important to notice and respond to suffering expressed in a work situation [12], helping compassion to become institutionalised within an organisation so it is self-sustaining [16]. As depicted in the title to a book by Worline and Dutton, compassion is "the quiet power that elevates people and organizations" [17].

Over recent years, compassion within health services has come under the spotlight following publicity surrounding poor episodes of care; in the United Kingdom, this included at Mid Staffordshire Hospital [18], University Hospitals of Morecombe Bay [19], and Winterbourne View care home [20]. In the busy reality of wards and surgeries, being cognisant of and feeling empowered to respond to suffering or distress can be difficult, if working in an environment that fails to provide the interpersonal and structural support required for compassion to flourish [21]. This has resulted in international concern and critique being expressed about contemporary healthcare cultures [22-24] where compassion is a common component of the values publicised by an organisation, yet staff can feel unsupported and under threat (e.g. job insecurity, failing to meet targets, reading negative publicity in the press).

In contrast to practice, little attention has been paid to the role of compassion as part of the processes associated with health services research, a field of investigation that studies "how social factors, financing systems, organizational structures and processes, health technologies, and personal behaviors, affect access to health care, the quality and cost of health care, and ultimately our health and wellbeing" [25]. This is possibly because it is seen as inherent in ethical concepts like beneficence - conducting research that will lead to the better care of others [26], and nonmaleficence - needing to be sensitive to what could constitute harm to participants [27]. Given that an ultimate goal of most health services research is to alleviate suffering or to improve patients' well-being, compassion could be seen as playing a role in such work. Furthermore, those conducting research with patients and carers who are facing difficulties due to their health situation (financial, psychological, physical, social) need to be supported so they do not encounter compassion fatigue, a state whereby individuals become overwhelmed by the feelings of others [28]. Compassion fatigue is said to affect concentration, increase errors and lead to a sense of incompetency [29], as people distance themselves or become closed off in order to cope. These two aspects of compassion in health services research - towards study participants and towards researchers - will be considered further in this paper.
A focus on this topic of compassion in the process and execution of research stemmed from the author's broader interest in compassion in healthcare. Whilst undertaking studies in this area, which included a consideration of organisational responsibilities, the role of self-compassion for health professionals, and the position of patients in enabling compassion to flourish in healthcare settings $[30,31]$, she reflected on the relevance of what had been written about compassion in healthcare to the research arena. Self-compassion, in particular, was a concept that she felt was important to address because she had found the work of writers like Neff helpful when encountering difficulties associated with the process of research (e.g. worrying about how to respond when hearing difficult stories from patients see below). A search for relevant articles was undertaken on the following databases - CINAHL, MEDLINE and ASSIA, using the search terms listed in Table 1; it highlighted a lack of writing on the topic, prompting the development of this paper.

\section{Compassion within the process of research}

Differing drivers underpin health services research compared to direct patient care, despite a unifying endpoint to improve people's circumstances. For example, researchers have metrics to meet in terms of funding success and publications, whilst clinical staff are subject to targets associated with factors such as waiting times and hospital-acquired infection rates. In both circumstances, performance indicators could put researchers and clinical staff at risk of ignoring the individual patient as they pursue more global outputs. We know this has occurred in the world of research from past, perhaps extreme, episodes of uncompassionate practices, whereby deliberate actions of investigators accentuated suffering. An infamous case was the Tuskegee study on syphilis that took place in Alabama USA, from the 1930s to 1970s. African-American men were encouraged to participate with enticements such as free medical care and meals, but they were not informed of the study's purpose, which was to explore the natural history of syphilis. Consequently, although there was no known treatment at the outset of the research, when penicillin became the standard way of managing syphilis, this knowledge was withheld from the study participants. More recently, in the UK in the 1980s and 1990s, it came to light that several hospitals were removing organs and tissues from babies who had died for

Table 1 Search terms used to locate relevant writing on the topic

- Compassion AND

- Research AND

- Health AND

- Conduct* OR undertak* OR produc* 
use in research, without parental permission. As might be expected, this caused considerable distress to parents when they found out. In both cases, utilitarianism may have underpinned decision making, whereby actions are regarded as justified because of a wider goal towards the 'greater good' in terms of a larger number of people benefiting from the research. Hence, utilitarianism relates to utility and asking questions about how actions affect those involved and the wider populace. It can be subdivided into act-utilitarianism, whereby yielding "the greatest level of happiness for the largest number of people is ethically correct" [32], and rule-utilitarianism, which contends that "a morally right action is simply an action conforming to the correct oral rule to the existing situation" [33]. From this perspective of utilitarianism, delayed compassion could have been proposed in terms of preventing suffering of others in the future through knowledge gained from the research. However, this runs counter to the Declaration of Helsinki [34], which states the importance of putting individuals' well-being before the progress of science.

In contrast to the relatively high profile cases mentioned above, day-to-day activities undertaken as part of a study may cause conflict between being compassionate and pressures associated with recruitment, data collection and analysis. For example, researchers are expected to be alert to distress exhibited by a study participant and to take appropriate action; this might include stopping data collection to see if the person wishes to continue and providing details of support services. A researcher may become desensitised to expressions of distress after interviewing many people, continuing to gather data despite the individual showing signs of unease (e.g. not making eye contact, self-soothing by rubbing their skin, wrapping arms around their body, wringing their hands). Alternatively, a researcher may overlook reservations expressed by an interviewee describing a situation that would be good for the study's findings. Hence, a series of tensions between expressing compassion and doing what is in the best interests of a study may exist during recruitment and data collection. Furthermore, analysis can involve interpreting or reducing participants' experiences, to provide a more global picture of a topic and to develop results that can be translated into practice. During this process, an individual's personal distress can be framed as problematic if failing to fit within an overall set of data (e.g. outliers).

It should be held in mind that compassion is something often enacted by researchers, which is not necessarily noticed as it becomes entangled with other aspects of the job, such as building rapport, putting participants at ease and treating individuals with dignity and respect. It is not always afforded the same status as more cognitive or technical skills [35]; even though being compassionate is complicated work [21], this might not necessarily be appreciated by those designing and managing investigations. One way to guard against this may be to have strong Patient and Public Involvement (PPI) within a project, although evidence is needed to support this notion. For PPI representatives to have an impact they need to be supported, with signs of distress or discomfort associated with this role identified and acted upon. This would not be the case if the principal investigator ignores a PPI representative who is struggling to make a contribution at a research meeting (favouring instead what academic colleagues have to say), leaving this person to feel alienated from the group.

Although the above discussion has outlined potential hazards associated with how research is conducted, participating in a study can be cathartic as individuals recall their experiences and feel empowered by having their voice heard [36]. However, this is not guaranteed, especially if a lack of time and resources mean that the balance tips in favour of getting the job of data collection completed, with participants simply treated as information providers. For a positive outcome to arise, a constructive connection between participant and researcher is required. One way researchers may try to connect with participants is opting to self-disclose, if someone enquiries about their background. It has been suggested that when it feels appropriate, self-disclosure can help with developing a rapport, but this should not draw focus away from the participant's experiences [37]. It links to the idea that it is easier to express compassion towards someone with whom we feel a similarity [38], and highlights how research can be a joint endeavour between participant and researcher, who come together to advance knowledge of a topic. That said, for researchers, being exposed to emotionally charged interactions during data collection means their own well-being should be considered [39].

\section{Self-compassion as a tool for researchers}

Rager [37] remarked that emotions have been ignored as part of the research process because they are not seen as objective; yet, researchers need to be prepared and equipped to cope with intense feelings that can arise when conducting a study, even if such emotional challenges cannot always be anticipated [35]. Researcher well-being is covered on application forms for ethics approval, but this may be seen as relating to physical risks (e.g. lone-worker policies) rather than emotional safety. Strategies to prevent or mitigate emotional distress that can come from working on a project should be considered at the planning stage [35] because undertaking health services research can lead to a plethora of emotional responses, from "uncomfortable to traumatic" [35]. For example, researchers may feel guilt/disquiet that they do not have a life limiting disease, or sorrow/anger at 
what a patient has had to endure, including poor encounters of health care. Researchers may undergo a strong emotional response when identifying closely with a participant's situation (e.g. if they have had the same condition, or are caring for someone with a similar illness) [40]. They can feel voyeuristic or prying during data collection, or may fear that they will not be liked or rejected by a participant [41]. Furthermore, analysis can involve in-depth engagement with stories of distress and suffering.

In light of the range of emotions that can emerge when conducting a study, compassionate principal investigators are required to prevent staff from feeling overwhelmed; failure to do so may lead to compassion fatigue, whereby being alongside patients as they recount their experiences is replaced by a sense of helplessness, isolation and numbness [39]. Researchers without a clinical background, new to the pain and challenges associated with health conditions, including issues to do with death and loss, may need supporting in this respect. However, just because a researcher has a clinical background should not mean someone is left to manage alone powerful emotions that arise when working on a study. In addition, a principal investigator should not assume a researcher is coping just because this individual does not state they are struggling. To avoid this, Pickett and colleagues [39] used debriefing; everyone working on their study came together to identify, share and manage intense responses to interviewees' stories of surviving a residential fire. Staff believed this stopped them from being besieged by difficult feelings and enabled them to continue hearing people's experiences of loss and despair. This relates to Hubbard et al.'s [35] suggestion that the burden of conducting fieldwork should be shared by a team and emotions associated with this not regarded as an individual responsibility. Alongside debriefing, Rager [37] proposed that journal writing, relaxation techniques and talking to friends and family members could be helpful. Hubbard and colleagues [35] wrote about "emotionally-sensed knowledge", which calls for researchers to reflect on issues such as "why is what the respondent saying making me angry? Why is the respondent not upset about their current situation? What does this tell me about how the respondent makes sense of his or her life?"

One approach to addressing researcher well-being is to cultivate self-compassion, a phenomenon, as noted above, associated with three key components [42]: self-kindness ("extending...understanding to oneself rather than harsh self-criticism and judgment"), common humanity ("seeing one's experiences as part of the larger human experience rather than as separating and isolating") and mindful acceptance ("holding one's painful thoughts and feelings in balanced awareness rather than over-identifying with them"). Self-compassion can help individuals feel less alone in their experience of distress [1] and represents a "positive self-attitude that should protect against the negative consequences of self-judgment, isolation and rumination" [43]. This may be important so researchers can remain open to the accounts of others, rather than being self-critical if believing they have not developed a connection with a study participant or for failing to follow-up on a specific question. Similarly, self-compassion may help researchers to contend with responses or comments from a study participant at odds with their own values. This was something written about by Throsby and Evans [44] who came to their research from a fat-activist stance. They documented the dilemma of whether to challenge negative attitudes or behaviours towards people who would be labelled as obese, recalling a sense of "collusion by default" when not doing so [44]. A self-compassionate stance to this dilemma would be a mindful acceptance that this is what happened at that specific moment and their response was human and understandable given the circumstances.

Self-compassion could also prove helpful in enabling researchers to be resilient to the setbacks associated with academia (e.g. having papers or funding bids rejected). Universities have been depicted as sites of sorrow and pain, in part because people can feel isolated in their work [10]. Gallos [45] went as far as to depict academic settings as "toxic trenches" due to turnover, reorganisation, budget cuts and job insecurity. Consequently, it is argued that policies and practices should be in place that emphasise the human side of academic organisations $[6,16,45]$. Compassion towards self and others could form part of such endeavours.

\section{Practical implications}

Those leading on a study should consider the well-being of researchers involved in data collection and analysis, to ensure they are not overwhelmed by these processes. Being proactive, rather than responding to events that occur is important, because researchers may need to feel permitted to raise such difficulties. Hence, regular debriefing, as referred to above, may be helpful in this respect. Furthermore, introducing researchers to the notion and principles associated with self-compassion and how to cultivate this offers another way to support these individuals in their work-role. This may help to ensure they are open to distress expressed by research participants, enabling them to respond by noticing and then acting to alleviate it. In this respect, questions for research teams to contemplate include:

- How do we address distress and suffering that may be exhibited by research participants?

- How do we ensure that researchers do not overlook this in the drive to collect and analyse data to a deadline? 
- How do we attend to and seek to uphold the emotional well-being of researchers involved in data collection and analysis?

\section{Conclusions}

The principle of compassion (towards self as well as others) is an area to consider during the conduct and production of health services research. In part this relates to the need to be attentive to suffering and distress that can transpire when participating in research, and ensuring that alleviating this is a priority, above the demands of study completion. Furthermore, it is important to address the emotional impact of data collection and analysis on researchers, who must be seen as human beings at risk of vicarious suffering when working with patients, if there is a lack of adequate organisational support. Hence, safeguards are required to protect researchers' well-being, enabling them to continue to perform optimally in their role. Cultivating self-compassion could form part of such work. Likewise, developing compassionate cultures in academic settings might prove helpful.

\section{Abbreviations}

PPI: Patient and Public Involvement

\section{Acknowledgements}

Thank you to colleagues at Warwick Research in Nursing for their comments on the manuscript, and to the reviewers of the paper for their helpful suggestions.

\section{Author contributions}

The author developed ideas in and wrote the paper.

\section{Funding}

Not applicable.

\section{Availability of data and materials}

Not applicable.

\section{Ethics approval}

Not applicable because this paper is not based on empirical data.

\section{Consent for publication}

Not applicable.

\section{Competing interests}

The author declares she has no competing interests.

Received: 19 October 2017 Accepted: 2 January 2018

Published online: 10 January 2018

\section{References}

1. Gilbert P. The compassionate mind. London: Constable; 2013.

2. Gilbert P, Catarino F, Duarte C, Matos M, Kolts R, Stubbs J, Ceresatto L, Duarte J, Pinto-Gouveia J, Basran J. The development of compassionate engagement and action scales for self and others. J Compassionate Health Care. 2017:4:4.

3. Sinclair S, Kondejewski J, Raffin-Bouchal S, King-Shier KM, Singh P. Can selfcompassion promote healthcare provider well-being and compassionate care to others? Results of a systematic review. Appl Psychol Health Well Being. 2017;9:168-206.

4. Neff K. Self-compassion: an alternative conceptualization of a healthy attitude toward oneself. Self Identity. 2003;2:85-101.

5. Duarte J, Pinto-Gouveia J, Cruz B. Relationships between nurses' empathy, self-compassion and dimensions of professional quality of life: a cross-sectional study. Int J Nurs Stud. 2016;60:1-11.
6. Atkins PWB, Parker SK. Understanding individual compassion in organizations: the role of appraisals and psychological flexibility. Acad Manag J. 2012;37:524-46.

7. West M, Eckert R, Collins B, Chowla R. Caring to change: how compassionate leadership can stimulate innovation in health care. London: The King's Fund; 2017.

8. Dutton J, Lilius JM, Kanov J. The transformative potential of compassion at work. In: Piderit SK, Cooperrider DL, Fry RE, editors. Handbook of transformative cooperation: new designs and dynamics. Palo Alto: Stanford University Press; 2007. p. 107-26.

9. Grant A, Dutton JE, Rosso B. Giving commitment: employee support programs and the prosocial sensemaking process. Acad Manag J. 2008;51:898-918.

10. Frost PJ, Dutton JE, Worline MC, Wilson A. Narratives of compassion in organization. In: Fineman S, editor. Emotion in organizations. 2nd ed. London: Sage; 2000. p. 25-45.

11. O'Donohoe A, Turley D. Compassion at the counter: service providers and bereaved consumers. Hum Relat. 2006:59:1429-48.

12. Dutton JE, Frost PJ, Worline MC, Lilius JM, Kanov J. Leading in times of trauma. Harvard Business Rev. 2002;January:54-61. https://www.ncbi.nlm.nih. gov/pubmed/12964467.

13. Ballatt J. Healthcare culture and intelligent kindness in practice. In: Hewison A, Sawbridge $Y$, editors. Compassion in nursing: theory, evidence and practice. London: Palgrave; 2016. p. 92-105.

14. Dutton JE, Worline MC, Frost PJ, Lilius J. Explaining compassion organizing. Admin Sci Quart. 2006;51:59-96.

15. Bettenhausen K, Murnighan JK. The emergence of norms in competitive decision-making groups. Admin Sci Quart. 1985;30:359-72.

16. Lilius JM, Worline MC, Dutton JE, Kanov JM, Maitlis S. Understanding compassion capability. Hum Relat. 2011;64:873-99.

17. Worline MC, Dutton JE. Awakening compassion at work: the quiet power that elevates people and organizations. Oakland: Berrett-Koehler; 2017

18. Francis R. The mid Staffordshire NHS foundation trust public inquiry: final report. London: The Stationery Office; 2013.

19. Kirkup B. The report of the Morecambe Bay investigation. 2015. www.gov. uk/government/uploads/system/uploads/attachment_data/file/408480/ 47487 MBI_Accessible v0.1.pdf (Accessed 10 Oct 2017).

20. Department of Health. Transforming care: A national response to Winterbourne View Hospital. 2012. www.gov.uk/government/uploads/system/ uploads/attachment_data/file/213215/final-report.pdf (Accessed 10 Oct 2017).

21. Tierney S, Seers K, Tutton E, Reeve J. Enabling the flow of compassionate care: a grounded theory study. BMC Health Serv Res. 2017;17:174.

22. Lee TH. An epidemic of empathy in healthcare. New York: McGraw-Hill; 2016.

23. Sawbridge $Y$. The emotional labour of nursing. In: Hewison A, Sawbridge $Y$, editors. Compassion in nursing: theory, evidence and practice. London: Macmillan; 2016. p. 136-51

24. Youngson R. Time to care. Rebelheart: Raglan; 2012.

25. Lohr KN, Steinwachs DM. Health services research: an evolving definition of the field. Health Serv Res. 2002;37:15-7.

26. Beauchamp TL, Childres JF. Principles of biomedical ethics. 5th ed. Oxford: Oxford University Press; 2001

27. Burns N, Grove SK. The practice of nursing research: conduct, critique and utilization. 5th ed. St Louis: Saunders; 2005.

28. Ghisoni M. The components of compassion. In: Hewison A, Sawbridge $Y$, editors. Compassion in nursing: theory, evidence and practice. London: Palgrave; 2016. p. 106-18.

29. Markaki A. Understanding and protecting against compassion fatigue. In: Shea S, Wynyard W, Lionis C, editors. Providing compassionate healthcare: challenges in policy and practice. London: Routledge; 2014. p. 214-31.

30. Tierney S, Seers K, Tutton E, Reeve J. Enabling the flow of compassionate care: A grounded theory study. BMC Health Services Research. 2017;17:174. https://www.ncbi.nlm.nih.gov/pubmed/?term=Enabling+the+flow+of +compassionate+care\%3A+A+grounded+theory+study.

31. Tierney S, Ozer CT, Perry S. Having the 'headspace' for compassion towards self and others: a qualitative study of medical students' views and experiences. Teach Learn Med.[in press]

32. Israel M, Hay I. Research ethics for social scientists. London; Thousand Oaks; New Delhi: Sage; 2006

33. Harsanyi JC. Rule utilitarianism, equality and justice. Soc Philos Policy. 1985;2:115-27.

34. World Medical Association. Declaration of Helsinki. 2013. www.wma.net/ policies-post/wma-declaration-of-helsinki-ethical-principles-for-medicalresearch-involving-human-subjects/ (Accessed 10 Oct 2017). 
35. Hubbard G, Backett-Milburn K, Kemmer D. Working with emotion: issues for the researcher in fieldwork and teamwork. Int I Soc Res Method. 2001;4:119-37.

36. Hutchinson S, Wilson M, Wilson H. Benefits of participating in research interviews. Image J Nurs Sch. 1994:26:161-4.

37. Rager KB. Compassion stress and the qualitative researcher. Qual Health Res. 2005;15:423-30.

38. De Steno D. Compassion and altruism: how our minds determine who is worthy of help. Behav Sci. 2015;3:80-3.

39. Pickett M, Walsh Brennan AM, Greenberg HS, Licht L, Deignan WJ. Use of debriefing techniques to prevent compassion fatigue in research teams. Nurs Res. 1994:43:250-2.

40. Johnson $\mathrm{N}$. The role of self and emotion within qualitative sensitive research: a reflective account. Enquire. 2009;2:191-214

41. Kisfalvi V. Subjectivity and emotions as sources of insight in an ethnographic case study: a tale of the field. M@n@gement. 2006;9:117-35.

42. Neff KD. The development and validation of a scale to measure self-compassion. Self Identity. 2003;2:223-50.

43. McPherson S, Hiskey S, Alderson Z. Distress in working on dementia wards - a threat to compassionate care: a grounded theory study. Int J Nurs Stud. 2016; 53:95-104.

44. Throsby K, Evans B. 'Must seize every opportunity?' Complicity, confrontation and the problem of researching (anti-) fatness. Crit Public Health. 2013;23:331-44

45. Gallos JV. Learning from the toxic trenches: the winding road to healthier organizations - and to healthy everyday leaders. J Manage Inquiry. 2008;17: 354-67.

\section{Submit your next manuscript to BioMed Central and we will help you at every step:}

- We accept pre-submission inquiries

- Our selector tool helps you to find the most relevant journal

- We provide round the clock customer support

- Convenient online submission

- Thorough peer review

- Inclusion in PubMed and all major indexing services

- Maximum visibility for your research

Submit your manuscript at www.biomedcentral.com/submit 